\title{
EL IDEAL DEL NUEVO CIUDADANO: ENTRE EDUCACIÓN MORAL, RELIGIOSA Y REPUBLICANA. ADAPTACIÓN DEL DECRETO ORGÁNICO DE INSTRUCCIÓN PÚBLICA PRIMARIA DE 1870 EN EL ESTADO SOBERANO DEL CAUCA*
}

\author{
Fernanda Muñoz
}

\section{Resumen}

En 1870, después de la revolución de 1860 que terminaría con la conformación de los Estados Unidos de Colombia en 1863, los administradores liberales radicales emprendieron su proyecto de implementar una educación laica, gratuita y obligatoria para todos los territorios que conformaban la Unión colombiana. Para tal efecto, expidieron el Decreto Orgánico de Instrucción pública primaria de 1870 cuya aplicación debía contar con la aceptación de los Estados Soberanos. En este contexto, el Estado Soberano del Cauca impuso sus propias condiciones con las que buscó defender su soberanía y atenuar el carácter laico del decreto. En esta dinámica además, encontramos que la educación moral, religiosa y republicana, sería la base sobre la que se modelaría el ideal del nuevo ciudadano.

Palabras clave: Decreto Orgánico de Instrucción pública primaria de 1870, ciudadanos, Iglesia y Estado, república liberal, Estado Soberano del Cauca.

\begin{abstract}
In 1870, after the 1860 Revolution that would end with the formation of the United States of Colombia in 1863, managers began their radical liberal project to implement a secular education, free and obligatory for all the territories that formed the Union of Colombia. For this purpose, was issued the Organic Act of public elementary instruction, in 1870, whose implementation should have been accepted by the Sovereign States. In this context, the Sovereign State of Cauca imposed its own conditions; they sought to defend its own sovereignty and attenuated the secular nature of the decree. In this dynamic we also can found that moral, religious and republican education was the base to model the ideal of the new citizen.
\end{abstract}

\footnotetext{
* Artículo de investigación tipo 2: de reflexión según clasificación de Colciencias. Es el resultado de un apartado del trabajo de grado presentado para optar por el título de historiadora de la Universidad del Valle, denominado "¿Quién quiere la educación? Proyecto educativo radical y padres de familia en el Estado Soberano del Cauca, 1870-1885".

*** Historiadora de la Universidad del Valle. Miembro del grupo Región reconocido por Colciencias en categoría A1.E-mail: fer020@yahoo.es.
} 
Key words: Organic Act of public elementary instruction, from 1870, citizens, church and state, liberal republic, Sovereign State of Cauca.

\section{Introducción}

Con el propósito de formar a los ciudadanos que legitimarían la república liberal establecida en la Constitución de $1863^{1}$, los administradores liberales radicales quienes se hallaban al frente del poder- expidieron el Decreto Orgánico de Instrucción pública primaria de 1870 (en adelante DOIP) que organizaba la instrucción pública primaria a nivel nacional, instituyendo la creación de escuelas normales y estableciendo la instrucción pública primaria obligatoria, gratuita y neutral en su orientación religiosa. Dado que la Constitución de 1863 otorgaba un alto nivel de autonomía a los Estados Soberanos, la implementación del DOIP a nivel nacional debía contar con su aceptación. A excepción del Estado de Antioquia y Tolima ${ }^{2}$, todos los Estados Soberanos, aunque con modificaciones, aceptaron el mencionado decreto.

Nuestro propósito en este artículo entonces, consiste en presentar los aspectos más controversiales del DOIP y las condiciones expuestas por el Estado Soberano del Cauca para su aceptación y aplicación. En este camino además, centraremos nuestro foco de atención en la representación del ciudadano republicano insertada en el decreto nacional, en las publicaciones del principal periódico difusor de la reforma, La Escuela Normal, y en los postulados y normativa del Estado Soberano del Cauca para aceptar el DOIP; contrastando dichas representaciones con la práctica de las escuelas. Así, intentaremos demostrar que el ideal del ciudadano moderno que buscó implantar la reforma escolar abogó por moldearlo bajo una educación moral, religiosa y republicana; y que, a pesar de que el Estado apeló por la separación de poderes entre Iglesia y Estado, esto no significó que la representación del ciudadano moderno debía prescindir de los valores y normas de conducta establecidas por el cristianismo.

\section{Adaptación del Decreto Orgánico de Instrucción pública primaria en el Estado Soberano de Cauca: defendiendo la soberanía, apelando a la moral y la religión}

Los asuntos más controversiales del DOIP giraron en torno a la defensa de la autonomía de los Estados Soberanos, la obligatoriedad de la enseñanza y el establecimiento de una educación laica. El primer punto del debate se centró en el primer artículo. Dicho artículo estipulaba que el Gobierno Federal dirigía e inspeccionaba la instrucción pública primaria en los territorios nacionales y en

\footnotetext{
${ }^{1}$ La república se llamó Estados Unidos de Colombia y estaba integrada por nueve Estados Soberanos: Antioquia, Bolívar, Boyacá, Cauca, Cundinamarca, Magdalena, Panamá, Santander y Tolima.

${ }^{2}$ Aunque inicialmente, en marzo de 1872, los conservadores del Estado del Tolima pusieron en marcha el decreto nacional, el acuerdo inicial entre el Estado y la Unión se disolvió en 1873 (Ramírez, 1998, p. 119).
} 
aquellos Estados que aceptaban las disposiciones del decreto (DOIP, 1871, 7 de enero, p. 2). Y como la Constitución de Rionegro otorgaba al Gobierno federal y a los Estados por igual derecho "fomentar" la instrucción pública, los críticos manifestaban que "fomentar" no significaba "dirigir" y menos centralizar. "Fomentar" no significaba crear, sino auxiliar, ayudar a mantener lo que existía, darle calor, impulso, protección ${ }^{3}$ (Arana, 1883, 5 de diciembre).

Otro asunto controversial giró en torno al artículo $\mathrm{N}^{\circ} 87$ del DOIP: la obligatoriedad de la educación para todos los niños entre los siete (7) y quince (15) años de edad, ordenando a los padres de familia enviar a sus hijos a una de las escuelas públicas del Distrito o haciendo que de otra forma se les diese instrucción suficiente (DOIP, 1871, 7 de Enero, p. 8). Al respecto, los críticos consideraban que la instrucción obligatoria era una falta contra la garantía de las libertades individuales consignadas en la Constitución de Rionegro y contra los derechos de los padres de familia. En este sentido, la disposición que suscitó mayores críticas, se centró en el establecimiento de una educación laica. El artículo $N^{\circ} 36$ del DOIP disponía que el gobierno no intervenía en la instrucción religiosa; pero las horas de escuela se distribuirían de manera que los alumnos tuviesen tiempo suficiente para que, según la voluntad de los padres, recibiesen dicha instrucción de sus párrocos o ministros(DOIP, 1871, 7 de Enero, p.5). La no obligatoriedad de la enseñanza religiosa, directamente relacionada con la enseñanza de religión católica, fue la base del debate público y la fuente de mayores discrepancias entre los diversos actores sociales ${ }^{4}$.

En el Estado Soberano del Cauca la aceptación e implementación del DOIP fue un proceso arduo. Se efectuaron dos Convenios sobre Instrucción pública primaria entre el Gobierno de la Unión y el Estado del Cauca, y varios proyectos de ley, que terminarían a finales del régimen liberal, con la expedición en 1884 del Decreto № 166 sobre Instrucción Pública Primaria. Las disposiciones de este decreto 166, especialmente en lo concerniente con la enseñanza de religión en las escuelas, ya visualizaban el nuevo viraje que se le estaba dando y se daría no sólo a la educación, sino al país. Una de las características fundamentales del DOIP, la no intervención del Gobierno en instrucción religiosa, fue sustancialmente modificada por el Estado caucano, y pronto, los postulados de la Constitución de

\footnotetext{
${ }^{3}$ Esta discusión fue reiterativa hasta la entrada en vigencia de la Constitución de 1886. En notas cruzadas entre el Poder Ejecutivo Nacional y el Secretario de Gobierno del Estado del Cauca sobre Instrucción Pública, se discute acerca de la potestad del Poder Ejecutivo de la Unión de organizar y dirigir la enseñanza pública oficial en todos los ramos. El Secretario de Gobierno del Cauca, R. M. Arana, exponía que según algunas disposiciones de la Constitución Nacional, la organización y dirección de la Instrucción pública no era un asunto delegado por dicha Constitución al Gobierno General, quedando esta facultad como exclusiva competencia de los Estados. En este sentido señalaba: El artículo 18 de la Constitución nacional dice: "Son de la competencia, aunque no exclusiva, del Gobierno General, las materias siguientes: $1^{\circ}$. El fomento de la Instrucción pública. Ante este artículo el Secretario de Gobierno del Cauca, manifestaba: Fomentar, no es crear, sino ayudar a mantener lo que existe, darle calor, impulso, protección".

${ }^{4}$ En enero de 1873, el Director General de Instrucción pública informaba que el artículo 36 del DOIP, "ha sido orijen de larga controversia"., S. (Pérez, 1873, 18 de enero, p. 10).
} 
Rionegro serían reemplazados por una nueva constitución, la de la Regeneración. Las principales reformas que el Estado del Cauca impuso como condición para aceptar el decreto nacional, versaron específicamente sobre dos (2) cuestiones fundamentales: mantener y defender la soberanía del Estado caucano, apelar a la enseñanza moral y atenuar la supuesta irreligiosidad del decreto.

Entrando en materia, encontramos que en septiembre de 1871 se publicó un proyecto de ley reformatorio de la instrucción pública, donde el presidente del Cauca, Tomás Cipriano de Mosquera, exponía que habiendo revisado el informe pasado del Secretario de Gobierno a la legislatura, sobre instrucción pública, específicamente en lo concerniente con el decreto del Poder Ejecutivo "aceptando condicionalmente" el DOIP, su Legislatura había resuelto no aceptar el decreto nacional por cuanto por él se amenazaba el poder de los Estados que formaban la Unión Colombiana. En el ejercicio de su soberanía, libertad e independencia entonces, y considerando "útil y necesario uniformar y organizar definitivamente en el Estado el sistema de educación e instrucción popular", el artículo segundo del proyecto de ley señalaba que la educación primaria o elemental sería organizada por el Estado con arreglo al sistema adoptado por el Poder Ejecutivo nacional en su decreto de 1 de noviembre de 1870, "en todo lo que fuere aplicable conforme a la ley" promulgada (Mosquera, 1871, 9 de septiembre, p. 1256). La aceptación del DOIP se supeditaba así, a la modificación de su primer artículo que facultaba al Gobierno Federal a dirigir e inspeccionar la instrucción pública primaria de los Estados que aceptasen sus disposiciones.

El primer Convenio establecido entre el Gobierno de la Unión y el Estado del Cauca tuvo lugar en abril de 1872. Su artículo primero ratificaba que el Gobierno del Estado organizaría, dirigiría e inspeccionaría la instrucción pública primaria en sus municipios y territorios. Además de contener dicha modificación sustancial, dicho convenio también reformó el título 3 del DOIP referente a la Educación y enseñanza, como mostraremos enseguida. El artículo № 30 del DOIP establecía: "La enseñanza en las escuelas no se limitará a la instrucción, sino que comprenderá el desarrollo armónico de todas las facultades del alma, de los sentidos i de las fuerzas del cuerpo" (DOIP, 1871, 7 de Enero, p.4). [i educacion moral i religiosa] ${ }^{5}$. Tal y cómo se puede ver, la parte quinta final del articulado, "i educacion moral i religiosa" (Salgar, 1872, 27 de abril, p. 129) introducía un elemento novedoso en el Cauca.

Igual tenemos la modificaron del artículo $\mathrm{N}^{\circ} 31$, cuyas disposiciones originales señalaban:

Es un deber de los Directores de escuela hacer los mayores esfuerzos para elevar el sentimiento moral [i religioso] de los niños i jóvenes confiados

\footnotetext{
${ }^{5}$ Las especificaciones que aparecen entre corchete y subrayadas indican las modificaciones al artículo original que estipulaba el convenio sobre Instrucción pública primaria entre el Estado de la Unión y el Estado del Cauca (así se hará sucesivamente con los artículos del DOIP).
} 
a su cuidado e instruccion, i para grabar en sus corazones los principios de piedad, justicia, respeto a la verdad, amor a su país, humanidad i universal benevolencia, tolerancia, sobriedad, industria i frugalidad, pureza, moderacion í templanza, i en jeneral todas las virtudes que son el ornamento de la especie humana, i la base sobre que reposa toda sociedad libre. Los maestros dirijirán el espíritu de sus discípulos [i a reconocer la excelencia de Dios Todopoderoso], en cuanto su edad i capacidad lo permitan, de manera que se formen una clara idea de la tendencia de las mencionadas virtudes para preservar i perfeccionar la organizacion republicana del Gobierno, i asegurar los beneficios de la libertad. (DOIP, 1871, 7 de Enero, p.

4)

En este apartado se efectuaron las siguientes modificaciones: en la línea que estipulaba "para elevar el sentimiento moral" se le agregaría "i religioso de los niños". Donde se establecía "los maestros dirijirán el espíritu de sus discípulos" se debía añadir "i a reconocer la excelencia de Dios Todopoderoso" (Salgar, 1872, 27 de abril, pp. 129-130). Otra modificación se consignó en el artículo 36 del DOIP, que originalmente establecía: "El Gobierno no interviene en la instrucción relijiosa; pero las horas de escuela se distribuirán de manera que a los alumnos les quede tiempo suficiente para que, según la voluntad de los padres, reciban dicha instruccion de sus párrocos o ministros" (DOIP, 1871, 7 de Enero, p. 5). Así, el Convenio reformó la enunciación del artículo: "La educación religiosa se dará a los niños en las escuelas, conforme a la voluntad de sus padres i por los preceptores que ellos elijan i sostengan, pues el Gobierno se abstiene de injerirse en las creencias relijiosas en observancia al inciso 16, artículo 15 de la Constitución nacional" (Salgar, 1872, 27 de abril, p. 130).

En 1872 entonces, el Estado del Cauca condicionó la aceptación del DOIP a las modificaciones que consignó en los artículos, cuyas disposiciones consideró peligrosas para mantener no sólo la soberanía del Estado, sino el orden social, específicamente en lo concerniente a la instrucción religiosa, que ahora se incluía dentro del Plan de estudios. La inclusión de la enseñanza religiosa en el artículo $N^{\circ} 30$ y la introducción del sentimiento religioso en el artículo $N^{\circ} 31$ del DOIP, nos permiten colegir la tendencia inicial del Estado caucano por mantener la religión como base de las conductas y el comportamiento social. No obstante, la inclusión de la enseñanza moral ${ }^{6}$, separada de la religiosa, nos permite cotejar la tendencia de los gobiernos liberales por insertar una moral portadora y portavoz de los valores y comportamientos que demandaría la formación del ciudadano moderno; pero sin la bifurcación, sino con el complemento, de una base religiosa. El sentimiento religioso no sería entonces, contrario a los nuevos valores y comportamientos del ciudadano moderno, el patriotismo y el progreso; sería la base de las relaciones sociales.

\footnotetext{
${ }^{6} \mathrm{La}$ moral, del latín mos-moris, costumbre, hace referencia al entrenamiento en hábitos recomendables (Gonzalbo, 1999, p. 10).
} 
Otro Convenio que se establecería entre el Gobierno de la Unión y el Estado del Cauca sobre Instrucción pública primaria, vería luz en junio de 1874. Su primer artículo confirmaba la facultad del Gobierno del Estado para organizar, dirigir e inspeccionar la instrucción pública primaria en sus Municipios y Territorios (Trujillo, 1874,10 de octubre, p. 2). El artículo $N^{\circ} 30$ del DOIP, cuyas disposiciones habían sido modificadas en el anterior convenio, nuevamente se reformaba. Ya no se incluiría como se efectúo anteriormente al final del artículo, "i educación moral i religiosa", sino que sólo se anexaría "y educación moral" (Trujillo, 1874, 10 de octubre, p. 3). Este cambio representa un viraje importante en la orientación de la enseñanza, pues ahora se reconocería que la educación religiosa no sería imprescindible en la representación del ciudadano moderno, y se le conferiría toda la confianza a la educación moral para imprimir en el alumno las normas de comportamiento que requeriría el nuevo individuo de la república. Aunque no podríamos precisar que la moral, sería totalmente laica, sin sustento religioso, lo que sí sería claro es que no se buscaba justificar el comportamiento y valores de los individuos bajo un andamiaje religioso, sino que se buscaba incrustar una moral, se podría decir laica, como parámetro normativo de la conducta social. Los individuos debían comportarse adecuadamente como una muestra de cumplimiento a las leyes del Estado, para mejorar la convivencia del cuerpo social, y no como un mandato divino.

Por otro lado, el Capítulo IV del DOIP, titulado Asistencia a las escuelas, específicamente la Sección primera, De la obligacion de asistir a las escuelas primarias, contenía una modificación significativa: se suprimían los apremios para obligar al envío y concurrencia de los niños a las escuelas (Trujillo, 1874, 10 de octubre, p.4). Dicha modificación quizá se estipuló teniendo en cuenta consideraciones como las del Director de Instrucción pública del Estado del Cauca en junio 1873, Manuel Quijano, quien en su informe al Presidente del Estado expresaba que debido a las condiciones geográficas y la diseminación de la población, era difícil llegar a la cabecera de la escuela, y por ello, consideraba que el sistema obligatorio era "impracticable e inconveniente":

Por entre nosotros, en que la poblacion está diseminada y dividida en distritos parroquiales de muchos quilómetros de extension a la redonda y en las cuales hay que atravesar valles profundos, cordilleras o serranías elevadas, ríos o ponentes caudalosas y peligrosas y hasta bosques y desiertos, para llegar a la cabecera en que apenas se encuentran el desamparo y la soledad con una que otra choza, la iglesia, la casa del Cura y la Cárcel, con la casa consistorial pajiza y otra con el titulo de Escuela; creo que á más de imposible, sería una verdadera crueldad castigar a los padres de familia que no puedan o no quieran mandar sus hijos a las Escuelas [...]. Rechazo, pues, el sistema obligatorio como impracticable e inconveniente; y ademas como depresiva de la dignidad de los padres de familia, a quienes la

\footnotetext{
${ }^{7}$ Para tener una idea de este proceso en el gobierno mexicano en su intento por difundir una moral sin andamiaje religioso y el sentido que le dio la sociedad, véase Staples, A. (1999), pp. 139-152.
} 
ley debe guardar respetuosas consideraciones, y a quienes se coloca con él en la dura alternativa de hacer un gran sacrificio ${ }^{8}$. (Archivo Central del Cauca (ACC), Archivo Muerto, t. I, 1873, paq. 121, leg. 32, s/f)

Empero, en el transcurso de la ejecución de esta medida, los funcionarios se mostraron preocupados por la inasistencia de los niños a la escuela. En febrero de 1875 el mismo Manuel Quijano, manifestaba su preocupación por la frecuente falta de asistencia de los niños a las escuelas, inquietándole que debido a la no obligatoriedad de la instrucción primaria, los Preceptores no aplicaban apremios a los alumnos matriculados que incurrían en la inasistencia. Aclaraba que la no obligatoriedad de la instrucción pública concernía a la libertad de los padres de familia en el sentido de enviar o no sus hijos a la escuela, más no impedía que los Preceptores aplicasen los castigos para con los alumnos matriculados en las escuelas, que en consecuencia, se hallaban sometidos a las reglas del establecimiento. Por ello, incitaba los Preceptores a imponer alguna de las penas que permitía el régimen orgánico escolar para hacerle frente a la situación (Quijano, 1875, 11 de febrero, p. 145).

Posteriormente, en octubre de 1875, se publicaba la ley $\mathrm{N}^{\circ} 48$ de 1875 cuyos lineamientos, respecto de la no obligatoriedad de la instrucción pública, desde el artículo 54 hasta el 59, señalaban: que por el acto de matricular un niño en una Escuela Pública, se contraía el compromiso civil de mantenerlo en ella durante el año escolar, por parte del padre, acudiente, guardador o responsable legal del niño. En cada Escuela habría un libro de matrículas, donde pondría la firma el responsable; en ese libro se especificaría el compromiso del padre, el guardador u otro, que consistía en hacer concurrir al niño puntualmente a la Escuela durante el año escolar. Los individuos que faltasen al compromiso anterior, incurrirán en una multa de diez (10) centavos a cincuenta (50) pesos, impuesta por el respectivo Alcalde (Conto, 1875, 21 de octubre, p. 322). Así que se afirmaba el compromiso de los padres de familia y los apremios que se les podía imponer si al matricular su hijo en la escuela, éste no asistía puntualmente a ella.

La cuestión de la obligatoriedad o voluntariedad de la Instrucción pública primaria, no fue un asunto claro desde la implementación del artículo $\mathrm{N}^{\circ} 13$ de la ley 39 de 1873. Todavía en junio de 1884, el Poder Ejecutivo emitía la resolución №14, cuyo propósito consistía en aclarar dicha cuestión:

De conformidad con el artículo 13 de la ley 39 de 1873, la instrucción pública primaria es voluntaria para el hecho de escoger el Establecimiento, yá sea de carácter oficial o particular, en el cual quieren los padres de familia hacer que sus niños reciban instrucción; más ella es obligatoria para todos los niños, una vez que hayan sido matriculados en las escuelas públicas del Municipio. Por consiguiente no pueden separarse ni ser

\footnotetext{
${ }^{8}$ Los subrayados son del documento original.
} 
retirados de ellas, a no ser que medien las causales de que habla el artículo 112 y previa la formalidad del 113 del Decreto "orgánico de la Instrucción Pública", de $1^{\circ}$ de noviembre de 1870 (Otero, 1884, 11 de julio, p. 2).

La supresión de los apremios para obligar al envío y concurrencia de los niños a las escuelas en el Convenio de 1874, constituyó así, un viraje significativo en el DOIP, en tanto que los padres de familia o acudientes, eran libres de enviar o no sus hijos a las escuelas, y por ello, esta cuestión no podía ser un asunto de discordia.

Por otro lado tenemos que la última modificación sustancial efectuada al DOIP en el Estado del Cauca, tuvo a lugar a finales del régimen liberal, con la expedición en septiembre de 1884, del Decreto N 166 sobre Instrucción Pública Primaria.La defensa de la soberanía sería más acérrima en este período. El artículo primero establecía que el Gobierno del Estado tenía a su cargo "la organización inmediata de la Instrucción Pública Primaria costeada por los Tesoros del Estado, sus Municipios y sus Distritos enuso de su soberanía"; ejerciendo de igual modo, la inmediata dirección e inspección del mismo ramo (Payán, 1884, 18 de octubre, p. 2). La especificación costeada por los Tesoros del Estado..., evidencia el constante debate que se experimentó en los últimos años de vigencia de la Constitución de Rionegro, entre las directivas del Gobierno nacional y las del Estado caucano, por la dirección, organización e inspección de la Instrucción pública.

Desde la ley 34 de 1883 el Gobierno del Estado caucano atribuía a sí mismo la inspección y dirección de la Instrucción pública. Pero el gobierno federal, considerando que tales atribuciones correspondían legalmente al Gobierno Nacional, suspendía y declaraba nulos los artículos 18 y 19 de la ley mencionada (Borrero, 1884, 2 de junio, p. 2). Posteriormente, el secretario de Instrucción pública de la Unión comunicaba al Secretario de Gobierno del Cauca, que la ley 106 de 1880 orgánica de la Instrucción pública, atribuía al Poder Ejecutivo Nacional la dirección y organización de los Establecimientos de Instrucción pública que costeaba la Nación, aclarando que los Estados tenían derecho de organizar y dirigir los establecimientos de Instrucción que deseasen, sin contrariar la Constitución o leyes nacionales (Borrero, 1884, 7 de junio, p. 3).

Siguiendo el espíritu de este debate, el Secretario de Gobierno del Estado del Cauca, comunicaba a los funcionarios públicos que la organización y dirección de los establecimientos públicos "sostenidos por sus propias rentas o por las que apropian del Estado, los Municipios y distritos", era una competencia exclusiva del Gobierno del Estado, sin la intervención de empleados nacionales, a menos que el mismo Gobierno les delegase alguna función ${ }^{10}$ (Ulloa, 1884, 7 de junio, p.

\footnotetext{
${ }^{9}$ El subrayado es nuestro. Las disposiciones completas del Decreto $\mathrm{N}^{\circ} 166$ de 1884 , se encuentran distribuidas en siete (7) números del Registro Oficial; desde el ํㅜ 337 hasta el №343.

${ }^{10}$ El subrayado es nuestro.
} 
3). El artículo primero del Decreto $\mathrm{N}^{\circ} 166$ entonces, abarca este debate y corrobora sus funciones en la dirección, organización e inspección de la Instrucción pública, defendiendo su soberanía y limitando el poder federal. En tanto, el artículo 5 del Título II, correspondiente a la Dirección de Instrucción pública primaria, seguía esta orientación, al estipular que el Poder Ejecutivo del Estado tenía a cargo la dirección general de la Instrucción Pública Primaria ${ }^{11}$ (Payán, 1884, 18 de octubre, p. 2), modificando radicalmente el DOIP y los anteriores convenios establecidos entre el Gobierno federal y el del Estado, en tanto que entre las atribuciones del director general no se establecía ninguna relación con la Dirección General nacional del ramo, ni con el Poder Ejecutivo nacional; la independencia de la Dirección de Instrucción pública del Cauca, con respecto a la nacional, se hacía categórica.

Siguiendo esta tendencia autonomista el artículo $N^{\circ} 198$ y 199 del título IV sobre Administración, capítulo II, sobre gastos, dejaba por fuera la participación del Gobierno nacional en gastos que anteriormente le competían como por ejemplo la provisión de útiles de enseñanza para las escuelas y el establecimiento de bibliotecas populares y circulantes, que ahora estaban en manos del Estado caucano ${ }^{12}$.Otra modificación relevante se efectúo en el ámbito de educación y enseñanza. Aunque el artículo $\mathrm{N}^{\circ} 30$ del DOIP conservó su contenido general, como se hizo en el Convenio de 1874 , en el que sólo se anexaba al final "y la educación moral":

Art. $66^{\circ}$. "La enseñanza en las escuelas no se limitará a la instruccion, sino que comprenderá el desarrollo armónico de todas las facultades del alma, de los sentidos y de las fuerzas del cuerpo, y la educación moral" (Payán, 1884, 25 de octubre, p. 3).

No aconteció lo mismo con las disposiciones del artículo N 36 del DOIP, cuya modificación constituye una de las principales características del nuevo viraje que experimentaría la Instrucción pública a puertas de la entrada del régimen de la Regeneración. La enseñanza de educación e instrucción religiosa y la permisividad en el ejercicio religioso, quedaba expresamente estipulada en los artículos 72 y 74 del Decreto № 166 de 1884:

\footnotetext{
${ }^{11}$ El subrayado es nuestro.

${ }^{12}$ El artículo $\mathrm{N}^{\circ}$ 198, establecía: "En el Estado del Cauca los gastos que ocasione la Instrucción pública primaria á su cargo, son de cuenta del Estado, de sus Municipios y distritos en los términos que establece este capítulo. Y el artículo $\mathrm{N}^{\circ}$ 199, estipulaba: Son de cargo del Estado: 1. Los que demande el sostenimiento de los alumnos y alumnas destinados para maestros; 2. La provisión de libros, cuadros, mapas, textos y demás útiles necesarios para la enseñanza en las Escuelas primarias del Estado; 3. El establecimiento de bibliotecas populares y circulantes; 4. El sostenimiento de los Inspectores departamentales; 5. La educación de ciertos niños ó jóvenes prevenida por actos legislativos especiales; 6. El auxilio que se señale como parte del sueldo de los Directores ó Subdirectores; 7. Es sostenimiento de escuelas rurales que se establezcan en los caseríos distantes de la cabecera de los distritos; 8. Los demás gastos decretados por las leyes y decretos legislativos, fijados en el presupuesto de gastos". Payán, 1884, 6 de noviembre, p. 2).
} 
Art. $72^{\circ}$. En todas las escuelas primarias en que se da instrucción pública, costeada o auxiliada con fondos del Estado, de los municipios o distritos, se dará educación e instrucción religiosa á los alumnos, conforme a la voluntad de ellos, de sus padres, tutores o curadores, y á falta de éstos sus acudientes ó recomendados. A este fin se expresará en la respectiva matricula la religión que profese cada alumno.

Parágrafo. Cuando los Directores no puedan dar, determinada instrucción religiosa, se nombrarán otros que la den, ó se contratarán maestros para ello, pudiéndose recibir tal instrucción fuera de las escuelas, según la voluntad y por cuenta de sus padres, de los preceptores que éstos designen. (Payán, 1884, 25 de octubre, p. 3)

Art. $74^{\circ}$. Es permitido a los alumnos de las escuelas todo ejercicio religioso. En consecuencia, deben asistir los domingos y días solemnes de fiesta á las prácticas y ceremonias religiosas de su respectivo culto, y cumplir los deberes que éste les impone; pero siempre presididos por el empleado del Establecimiento que determine el Superior de él y en los Templos o Capillas respectivos, prefiriendo los anexos á los Establecimientos, y á la hora que fijen los Directores. (Payán, 1884, 29 de octubre, p. 1)

Si bien es cierto, el artículo $N^{\circ} 36$ del DOIP, no prohibía la enseñanza religiosa ${ }^{13}$, tampoco expresaba explícitamente que en las escuelas primarias se daría educación e instrucción religiosa, como claramente lo estipulaba el artículo $N^{\circ} 72$ del referido decreto. Además, la especificación cuyos preceptos estipulaban que dicha instrucción se daría en los establecimientos costeados o auxiliados con fondos del estado, municipios y distritos, evidencia el conflicto descrito anteriormente por la defensa de la soberanía, la autonomía de los establecimientos costeados por el Estado y demás, de impartir enseñanza religiosa, en aparente oposición a los establecimientos costeados con fondos nacionales.

Ahora bien, aunque el artículo $N^{\circ} 72$ dejase a libre albedrío la enseñanza religiosa, respetando la voluntad de los niños, padres o acudientes; el artículo $\mathrm{N}^{\circ}$ 74 da cuenta de la nueva orientación en términos de incitar a la práctica de un culto religioso en tanto que permitía a alumnos de las escuelas todo ejercicio religioso, recordando el deber de practicar las ceremonias y deberes del respectivo culto. Si efectivamente, no podemos afirmar que en las escuelas regidas por el gobierno nacional o por los que acogieron las disposiciones íntegras del DOIP, no se practicaba el ejercicio religioso de asistir con alumnos a misa, o de dar apertura a una escuela con una ceremonia precedida por un sacerdote católico $^{14}$, como evidentemente aconteció; también es cierto, que las

\footnotetext{
${ }^{13}$ Recordemos que el Art. $36^{\circ}$ del DOIP estipulaba que: "El Gobierno no interviene en la instrucción relijiosa; pero las horas de escuela se distribuirán de manera que a los alumnos les quede tiempo suficiente para que, según la voluntad de los padres, reciban dicha instrucción de sus párrocos o ministros".

${ }^{14}$ Para mencionar sólo un ejemplo, encontramos que cuando el Estado Soberano del Cauca se regía por las disposiciones del DOIP -con sus respectivas reformas-, en 1875 en el municipio de Caldas se estableció una
} 
estipulaciones del DOIP no declaraban ni incitaban a la práctica de ningún ejercicio religioso, como sí se especifica en el artículo $N^{\circ} 74$ del Decreto $\mathrm{N}^{\circ} 166$.

Es más, entre las materias que señalaba el nuevo decreto, el artículo $N^{\circ} 76$ establecía que se enseñase religión ${ }^{15}$, y la enseñanza de moral, debía comprender según el artículo $\mathrm{N}^{\circ} 88$ : "el conocimiento de los deberes del hombre para con su Creador, para con la Patria, para con la familia, para consigo mismo y para con los demás hombres"16 (Payán, 1884, 29 de octubre, pp. 1-2). Y es que la nueva orientación de la enseñanza había sido advertida claramente en los primeros meses del año 1884 por el presidente Eliseo Payán: "que la enseñanza en el Estado no será completamente laica, sino religiosa para cada educando según el culto a que pertenezca, o que sus padres exijan" (Payán, 1884, 7 de febrero, p. $4)$.

Con estas disposiciones queda al descubierto el nuevo rumbo que se daría a la instrucción pública, situando nuevamente -como se efectúo en el Convenio de abril de 1872-, la enseñanza de religión en el plan de estudios. Esto, sin contrariar con la enseñanza de moral que según el artículo $N^{\circ} 88$, debía dar conocimiento de los deberes del hombre con su Creador y su patria, en total complementariedad con el ideal del ciudadano republicano; un ciudadano con bases religiosas y conocedor de los deberes para con su Creador y su Patria; deberes, y no un mandato divino, instituidos como base de las relaciones sociales. El ciudadano que se buscaba crear entonces, debía estar en armonía con su creador y su patria, y la religiosidad no contrariaba con la representación del ciudadano de fines del régimen federalista en el Estado Soberano del Cauca, ni con las disposiciones del decreto nacional de 1870; observemos tal situación.

\section{El ideal del ciudadano moderno: entre educación moral, religiosa y republicana}

El Estado laico ${ }^{17}$ que se buscaba crear con la no intervención del gobierno en la instrucción religiosa -como lo señalaba el artículo $N^{\circ} 36$ del DOIP-, denotaba

escuela pública cuyo acto de apertura se efectúo en la Iglesia donde se celebró una misa en acción de gracias a la virgen, pues la escuela era de niñas (Iragori, 1875, 18 de febrero, p. 154).

${ }^{15}$ El artículo 76 del Decreto $N^{\circ} 166$ señalaba: "La enseñanza en las Escuelas elementales de primera clase abraza las siguientes materias: Lectura, Escritura, Aritmética, el sistema legal de pesas y medidas, elementos de la lengua castellana, Dibujo lineal, ejercicios de Composición y Recitación, Nociones generales de Higiene, de Geografía y de Historia patria, Urbanidad, Moral, Religión y Derechos y Deberes del ciudadano, Gimnástica y Calisténica” (Payán, 1884, 29 de octubre).

${ }^{16} \mathrm{El}$ subrayado es nuestro.

${ }^{17}$ En este punto es menester tener en cuenta que el término laico en nuestro contexto, se aplica al ámbito de las relaciones institucionales entre Iglesia (católica) y Estado, y que denota un significado diferente del término secularización, cuyo margen de acción es más extenso y complejo. Siguiendo las apreciaciones de 
claramente la intención de los administradores liberales radicales por instaurar una demarcación precisa entre dos instituciones que debían ser independientes, la Iglesia y el Estado; por consiguiente, la tutela de la educación, como asunto de Estado $^{18}$, no debía seguir en manos de la institucionalidad católica.

No obstante, esa tendencia por separar dos entidades distintas, Iglesia y Estado, no significa, según nuestro criterio, una apuesta por el indiferentismo religioso; ni que la formación del ciudadano moderno debía prescindir de los valores y comportamientos del cristianismo. Es más, apelamos a que la religiosidad no contrariaba con la representación del ciudadano moderno, pues las virtudes que se debían inculcar en los niños y jóvenes, considerando las disposiciones del DOIP, estaban en armonía con los principios cristianos; además, algunos artículos del principal periódico difusor de la reforma escolar radical, $\mathrm{La}$ Escuela Normal, consignaban en sus páginas que la organización de la república colombiana debía basarse sobre la idea de justicia contenida en el cristianismo, y que la ciencia devenía de un Dios -cristiano por supuesto-.

En el texto adoptado por la Dirección general de Instrucción pública: INSTRUCCION POPULAR. Educación americana, en el capítulo II. Objeto de la educación, se exponía que la educación debía conformarse con los principios de organización, civilización y religión de cada país. La república de Colombia entonces contaba con las siguientes ideas:

Cárdenas Ayala, la secularización, en el sentido moderno, es definido “como un proceso de construcción de ámbitos especializados para lo político y lo religioso, en el marco de una esfera pública racionalizada en donde el Estado garantiza la coexistencia respetuosa de instituciones religiosas diversas y concurrentes y en donde el sujeto (individual) decide libremente pertenecer o no a una comunidad religiosa determinada, sea ésta a no la de sus padres y aun no tener afiliación religiosa alguna" (p. 198); y el término laicidad es más restringido, pues se aplica al ámbito de relaciones institucionales (p. 206). Cárdenas Ayala, E. (2007). Hacia una historia comparada de la secularización en América Latina.En Palacios, G. (Coord.), Ensayos sobre la nueva historia política de América Latina, siglo XIX (pp. 197-211). México: El Colegio de México, Centro de Estudios Históricos. Consideramos pertinente establecer esta aclaración pues los términos laicidad y secularización tienden a usarse indistintamente, y tal frecuencia ha impelido a caer en dos errores. El primero, creer que el proyecto político de los liberales radicales, cuya base era la construcción de un Estado laico donde se hacía imprescindible la separación entre Iglesia (católica) y Estado, significara irreligiosidad de parte de éstos, y que por éste medio, la sociedad necesariamente avanzaba hacia una secularización inminente y progresiva; cuando es sabido que los procesos sociales y culturales son más complejos. Segundo, que frecuentemente los términos laicización y secularización se relacionan con descristianización, llegando incluso a asimilar laicismo con ateísmo, cuando sus significados y aplicaciones eran otros; consideramos además, que la secularización no conlleva obligatoriamente hacia una irreligiosidad y que más bien, existe una relación entre secularización y religiosidad. En este sentido, las apreciaciones de Roberto Blancarte en su artículo "Modernidad, secularización y religión; la Iglesia católica, el Estado y la sociedad mexicana en el umbral del siglo XXI", aunque hacen referencia a un siglo diferente al nuestro, constituye un ejemplo sugerente de una relación entre religiosidad y "secularidad". Véase Blancarte, R. (1995). Modernidad, secularización y religión. La Iglesia católica, el Estado y la sociedad mexicana en el umbral del siglo XXI. En Blanco, J. J. y Woldenberg, J. (Comp.), México a fines de siglo, Tomo II, (pp. 152-188). México: FCE.

${ }^{18}$ En esta época la educación, que buscaba desprenderse de la institucionalidad católica, entraría a formar parte de un asunto de Estado, e irremisiblemente, dependería de la dirigencia política del momento; el campo educativo era una cuestión política, por consiguiente, no era aún un campo autónomo. 
1. La idea de su gobierno, contenida en la constitución.

2. La idea de la ciencia moderna, desarrollada en la civilización-moderna.

3. Y, la idea de la justicia contenida en el cristianismo (La Escuela Normal, Periódico Oficial de Instrucción Pública, 1871, 14 de enero, p. 23).

4. En este punto es relevante señalar que la idea de ciencia no se contrariaba con las creencias religiosas; la idea de ciencia que se insertaba en el texto, la verdadera ciencia, concluía citando una ley de Hooker: "De ella no puede saberse más sino que su asiento está en el seno de Dios; que su voz es la armonía del mundo" (Idea de ciencia, 1871, 21 de enero, p. 39). Así que la educación y la correlativa civilización que se alcanzaría con ella, no reñía con la idea de creer en un Dios creador del universo, sino que la república de Colombia descansaba sobre un firme pilar: el cristianismo.

Ahora bien, es inobjetable que en el imaginario del liberalismo radical el orden de la patria, la libertad y la ciudadanía, constituían los principales elementos del discurso republicano, ávido de formar ciudadanos dispuestos a defender el proceso de modernización y, por supuesto, a la república ${ }^{19}$ (Alarcón, 2000, pp. 53$57)$. Pero, en este imaginario, donde las escuelas tenían el propósito de formar "hombres sanos de cuerpo i espíritu, dignos i capaces de ser ciudadanos i magistrados de una sociedad republicana i libre"20 (DOIP, 1871, 7 de enero , p. 4).), se buscaba inculcar en los niños y jóvenes principios de "piedad, justicia, respeto a la verdad, amor a su país, humanidad i universal benevolencia, tolerancia, sobriedad, industria i frugalidad, pureza, moderación i templanza" ${ }^{21}$ (DOIP, 1871, 7 de enero, p. 4); principios que no discrepaban con los preceptos del cristianismo.

La relación de complementariedad entre la representación del ciudadano moderno y el sentimiento religioso encuentran mayor sustento en el inciso 3 del artículo $N^{\circ} 82$ del DOIP. Según sus estipulaciones uno de los deberes del director de escuela consistía en

\section{Atender mui particularmente a la educacion moral, relijiosa i republicana de los alumnos, empleando, sin hacer uso de cursos}

\footnotetext{
${ }^{19}$ En este proceso de modelación del hombre requerido por la nueva república, no sólo la escuela, sino los periódicos, folletos y libros escolares, desempeñaron un papel importante en la difusión del discurso republicano. Alarcón Meneses señala que los libros escolares mostraban las bondades de la república, las razones para su defensa, la trascendencia de la nación y del hombre convertido en ciudadano y aleccionaban a los estudiantes, a través del consejo moral y el aprendizaje memorístico, para que reconocieran, valoraran, y observaran la importancia y el cumplimiento de las reglas de urbanidad, fundamento de la "sociedad civilizada" (pp. 56-57).

${ }^{20}$ Artículo $\mathrm{N}^{\circ} 29$ del DOIP.

${ }^{21}$ Artículo $\mathrm{N}^{\circ} 31$ del DOIP.
} 
especiales, toda su intelijencia i el método mas adecuado, a fin de grabarles indeleblemente convicciones profundas acerca de la existencia del Ser Supremo, creador del universo, del respeto que se debe a la relijion i a la libertad de conciencia; persuadirlos con el ejemplo i la palabra a que sigan sin desviarse el sendero de la virtud, predicarles constantemente el respeto a la lei, el amor a la patria i la consagracion al trabajo ${ }^{22}$. (DOIP, 1871,7 de enero, p. 7)

La disposición que indicaba a los directores atender mui particularmente la educación moral, religiosa y republicana de los alumnos, constituye un ejemplo puntual de la convivencia entre dos tipos de enseñanza que no chocaban, la religiosa y la republicana. El deber de inculcar en los niños la existencia del Ser Supremo, y el respeto que se debía a la religión y a la libertad de conciencia, muestra la coexistencia entre dos vertientes: la religiosa y la liberal, que no discrepaban con el ideal de ciudadano que se buscaba formar. De hecho, en la práctica la estipulación de grabar en el corazón de los niños la existencia de un Ser Supremo, se cumplía. Trayendo a colación algunas planas de los alumnos de la Escuela de Vitoncó, Huila, ${ }^{23}$ en agosto de 1873, podemos apreciarlo. La plana de la primera clase, además de versar sobre el respeto que se debía a los padres, anotaba: "Existe un Dios a existido siempre y no puede dejar de existir jamas. El amor de Dios es el mas grande". Otra plana, también de la primera clase señalaba: "El hombre debe adorar a Dios con su espiritu y con su cuerpo en público i en privado como a su principio i fin i como a su único y soberano bien" (ACC, Archivo Muerto, t. I, 1873, paq. 121, leg. 32, s/f). La plana de un alumno de octava clase va más allá al proclamar a la Iglesia católica, la institución, como la única que mereciese tal nombre:

Uno de los caracteres mas evidentemente divinos del catolicismo, es la institucion de la Iglesia. La Iglesia es el antemural contra el cual se estrellan los embates del orgullo. Ella es la manifestacion permanente de Jesucristo; y sin ella el Evangelio no seria mas que una letra muerta, los frutos de la redención serian perdidos para la humanidad i en vano habría corrido la sangre del Justo sobre el calvario.

La Iglesia católica es la única que merece el nombre de Iglesia las otras sectas tienen escuelas donde se disputa esta en la Iglesia donde se cree. (ACC, Archivo Muerto, t. I, 1873, paq. 121, leg. 32, s/f)

Esta última plana quizá disentía con los preceptos de los administradores liberales ya que se superponía a la Iglesia católica, como institución, sobre los demás cultos; cuando lo que ellos buscaban era una libertad de conciencia, donde

\footnotetext{
${ }^{22}$ Artículo $\mathrm{N}^{\circ} 82$ del DOIP. Los subrayados son nuestros.

${ }^{23}$ El territorio del Huila, según informe del secretario de gobierno del Estado Soberano del Cauca en julio de 1872, fue creado a la par con el Territorio del Darien, y al primero corresponde la población de Vitoncó (Quijano, M. W., p. 12).
} 
la institucionalidad católica no tuviese ninguna preferencia ${ }^{24}$. Pero como existe una gran distancia entre el discurso y la práctica, aquí nos percatamos de una de sus secuelas.

En un número de La Escuela Normal además, explícitamente se excitaba a proclamar por medio de un himno escolar la existencia de un Ser Supremo representado en el Padre Nuestro:

\section{HIMNOS DE ESCUELA \\ (Con música alemana) \\ EL PADRE NUESTRO}

Padre nuestro, mi clamor

Te proclamo con anhelo;

Oh divino Redentor,

Cuyo trono está en el cielo!

Que tu nombre con fervor

Se bendiga i con amor.

I tu reino venga á nos

Tu querer acá en el suelo

Sólo se haga, inmenso Dios,

Como lo hacen en el cielo.

Si se oye aquí tu voz

Por un cielo ya habrá dos.

Danos, grande i buen Señor, Nuestro diario sustento,

I perdona nuestro error [...] (Muñoz, 1876, 4 de marzo, pp. 380-381)

El Estado Soberano del Cauca tampoco se quedaba atrás en la labor de reconocer a un Ser Supremo. Así lo constata la designación de himnos para el uso de las escuelas antes de iniciar las lecciones de la mañana; veamos un aparte:

¡SER SUPREMO, infinito, Uno solo en la esencia, Que en los cielos habitas sobre un jtrono de estrellas!

Pues que te agradan tanto Las efusiones tiernas

\footnotetext{
${ }^{24}$ Cuando nos referimos a Iglesia católica y religión católica, debe entenderse dos cosas diferentes; la primera representa a la Iglesia como institución; y la segunda, la religiosidad o creencias de sus adeptos; son dos planos diferentes: el de la esfera jurídica y el de la esfera cultural respectivamente.
} 
Del corazón sencillo,

Que vive en la inocencia:

Recibe ¡dulce padre!

¡Dios de la luz eterna!

Las que hoy te consagramos

Con filial reverencia [...] (Valencia, 1871, 21 de octubre, p. 1288)

Y al estipular que en el Colegio de niñas que se establecería en el antiguo monasterio del Carmen se recibirían alumnas internas, escogidas entre las familias pobres, que tuviesen principios sanos de moral, religión y educación (Mosquera, 1871, 9 de septiembre), el Estado caucano tampoco encontraba disonancia con los principios religiosos, cuyo requerimiento constituía un requisito para entrar en un colegio portador y portavoz de los ideales republicanos. De esta forma, constatamos que la independencia de dos (2) instituciones, Iglesia y Estado, y por consiguiente, la tutela de la educación en manos estatales -por la que abogaban los administradores liberales radicales-, no indicaba necesariamente que se debía prescindir de los códigos morales del cristianismo como base de las relaciones sociales, sino que tales principios ayudarían a preservar y perfeccionar la organización republicana del gobierno, y por ende, a formar al ciudadano. Como bien lo acota la historiadora Santos Delgado, aunque se reconoce que los radicales declaraban en sus discursos cierto anticlericalismo, y plantearon la separación entre Iglesia y Estado como instituciones que debían tener presencia en dos esferas diferentes; "la mayoría no llegaron a proponer la eliminación del catolicismo y ni siquiera del clero católico de la vida social colectiva ni individual. Las posiciones más anticlericales consistieron en una crítica a las actuaciones y comportamientos del bajo clero, de la jerarquía eclesiástica y del clero regular, sin pretender hacer una crítica a los planteamientos de la fe católica" (Santos, 2006, p. 175).

En este punto, es pertinente señalar que la separación de poderes entre Iglesia y Estado buscada por los administradores liberales, se basaba en el reconocimiento de dos órdenes de verdades: las verdades naturales, que eran percibidas directamente por las facultades propias de la razón humana, y las verdades sobrenaturales, que eran reconocidas por la revelación, y en las que no se creía, como decía el catecismo, "sino en virtud de un don de Dios, que es [era] la fe". De esta distinción resultaba que "las verdades morales i religiosas percibidas directamente por el espíritu humano sin el socorro de la revelacion, son [eran] el fundamento de la sociedad civil". Y, que "las verdades reveladas son [eran] el [del] dominio del sacerdocio, el cual afirma [ba] haber recibido la mision de conservarlas intactas, de explicarlas i de enseñarlas". Sobre esta distinción, se basaba la separación de la esfera de acción entre Iglesia y Estado, cuyos objetivos en la sociedad eran diferentes. Expresamente, el objetivo de la Iglesia católica consistía en "procurar a los hombres los medios de salvacion, haciéndoles conocer los dogmas, i administrándoles los sacramentos que fortifican 
[fortificaban] las almas i las elevan [elevaban] a Dios"; mientras que el objeto del Estado consistía en "procurar al hombre la posibilidad de desenvolver todas sus facultades, de tender a su perfeccion; en otros términos, de obtener su felicidad" (La Escuela Laica, 1873, 2 de Agosto, p.248).

Uno de los propósitos más evidentes de los administradores liberales radicales entonces, consistió en separar la esfera de acción entre Iglesia y Estado, cuyos objetivos eran diferentes, pero sin representar que tal propósito debía prescindir de los principios cristianos, ni que apelasen por un indiferentismo religioso. La idea de la educación americana que formaría al ciudadano de la república liberal era así: "la de una educacion, en hechos i en teoría, de conformidad con la idea de una república completa, de una república cristiana i de un desarrollo físico i moral de todas las facultades del individuo" (Objeto de la educación, 1871, 14 de enero, p. 22); una idea de educación que formaría al ciudadano moderno en los principios de la moral, de la religión, y, por supuesto, de la república.

\section{REFERENCIAS BIBLIOGRÁFICAS}

\section{Fuentes documentales}

Arana, R.M. (1883, 5 de diciembre). "Notas", en Registro Oficial, Órgano del Gobierno del Cauca, serie V ( $\left.{ }^{\circ} 277\right)$, p. 2.

Archivo Central del Cauca, Archivo Muerto, t. I, 1873, paq. 121, leg. 32.

Borrero, N. (1884, 2 de junio). "Instrucción pública". En Registro Oficial, Órgano del Gobierno del Cauca, serie V (n³08), p. 2.

(1884, 7 de junio). "Telegrama". En Registro Oficial, Órgano del Gobierno del Cauca, serie V (n³09), p. 3.

Conto, C. (1875, 21 de octubre). "Aviso Oficial". En El Escolar. Periódico Oficial de Instrucción pública del Estado Soberano del Cauca, t. I (n40), p. 322.

"Decreto Orgánico de Instrucción pública primaria (DOIP)". (1871, 7 de enero). En La Escuela Normal, Periódico Oficial de Instrucción Pública, tomo I ( $\left.n^{\circ} 1\right)$.

"Idea de ciencia". (1871, 21 de enero). En La Escuela Normal, Periódico Oficial de Instrucción Pública, tomo I (n³), p. 39.

Iragori, F. (1875, 18 de febrero). "Municipio de Caldas". En El Escolar, Periódico Oficial de Instrucción pública del Estado Soberano del Cauca, tomo I ( $\left.n^{\circ} 20\right)$, p. 154. 
"La Escuela Laica". (1873, 2 de Agosto). En La Escuela Normal, Periódico Oficial de Instrucción Pública, tomo IV (n¹35), p. 248.

La Escuela Normal, Periódico Oficial de Instrucción Pública (1871, 14 de Enero). Tomo I ( $\left.n^{\circ} 2\right)$.

Mosquera, T. C. (1871, 9 de septiembre). "Proyecto de Ley". En Gaceta Oficial, nº 363, p. 1256.

Muñoz, A. (1876, 4 de marzo). "Himnos de escuela". En La Escuela Normal, Periódico Oficial de Instrucción Pública, tomo VI (n²56), pp. 380-381.

Otero, F. A. (1884, 11 de julio). "Resolución $n^{\circ}$ 14". En Registro Oficial, Órgano del Gobierno del Cauca, serie V ( $\left.n^{\circ} 314\right)$, p. 2.

Payán, E. (1884, 7 de febrero). "Mensaje del Presidente del Estado Soberano del Cauca". En Registro Oficial, Órgano del Gobierno del Cauca, serie V ( $n^{\circ} 287$ ), p. 4.

(1884, 18 de octubre). "Decreto n 166". En Registro Oficial, Órgano del Gobierno del Cauca, serie V ( $\left.{ }^{\circ} 337\right)$, p. 2.

(1884, 25 de octubre). "Decreto n 166". En Registro Oficial, Órgano del Gobierno del Cauca, serie V (n³39), p. 3.

(1884, 29 de octubre). "Decreto n 166". En Registro Oficial, Órgano del Gobierno del Cauca, serie V (n॰340), p. 1).

(1884, 6 de noviembre). Registro Oficial, Órgano del Gobierno del Cauca, serie V ( $\left.\mathrm{n}^{\circ} 342\right)$, p. 2.

Pérez, S. (1873, 18 de enero). "Informe del Director Jeneral de Instrucción pública". En La Escuela Normal, Periódico Oficial de Instrucción Pública, tomo IV (n॰ 106 y 107), p. 10.

Quijano, M. J. (1875, 11 de febrero). "Inspección general”. En El Escolar, Periódico Oficial de Instrucción pública del Estado Soberano del Cauca, t. I ( $\left.n^{\circ} 19\right)$, p. 145.

Quijano, M. W. Informe del Secretario de Gobierno del Estado Soberano del Cauca, a la convención de 1872, Imprenta del Estado, Director, J. Clímaco Rivera, p. 12. 
Salgar, E. (1872, 27 de abril). "Convenio sobre Instrucción pública con el Estado del Cauca". En La Escuela Normal, Periódico Oficial de Instrucción Pública, tomo III ( $\left.n^{\circ} 69\right)$.

Trujillo, J. (1874, 10 de octubre). "Convenio". En Registro Oficial, Órgano del Gobierno del Cauca, año II (n 61).

Ulloa, J. D. (1884, 7 de junio). "Circular n²4". En Registro Oficial, Órgano del Gobierno del Cauca, serie V (n³09), p. 3.

Valencia, M. S. (1871, 21 de octubre). “Decreto”. Gaceta Oficial (n³69), p. 1288.

\section{Fuentes bibliográficas}

Alarcón Meneses, L.A (2000). "Patria, libertad y ciudadanía. El discurso republicano en los libros escolares durante el radicalismo". En Historia Caribe, vol. II (5), pp. 53-69.

Blancarte, R. (1995). "Modernidad, secularización y religión. La Iglesia católica, el Estado y la sociedad mexicana en el umbral del siglo XXI". En Blanco, J. J. y Woldenberg, J. (Comp.), México a fines de siglo, Tomo II. México: FCE. pp. 152-188.

Cárdenas Ayala, E. (2007). "Hacia una historia comparada de la secularización en América Latina". En Palacios, G. (Coord.), Ensayos sobre la nueva historia política de América Latina, siglo XIX. México: El Colegio de México, Centro de Estudios Históricos. pp. 197-211.

Gonzalbo Aizpuro, P. (1999). "Introducción". En Gonzalbo Aizpuro, P. (Coord.), Familia y educación en Iberoamérica. México: El Colegio de México, Centro de Estudios Históricos. pp. 9-20.

Ramírez Bahamón, J. (1998). Historia social de una utopía escolar. La Educación en el Estado Soberano del Tolima, 1861-1886. Neiva: Universidad Surcolombiana.

Santos Delgado, Adriana (2006). "La ambigüedad del radicalismo colombiano: El caso del Estado Soberano del Magdalena, 1868-1886". En Delibes Mateos, R. y Marchena Fernández, J. (Ed.), Mundos Indígenas. Sevilla: Aconcagua libros. pp. 171-188.

\section{Recibido: Octubre 3 de 2011}


Aprobado: Noviembre 29 de 2011 